\title{
Instituciones, música, niños y jóvenes en orquestas sinfónicas y bandas musicales
}

A partir de nuestra experiencia con diversas instituciones dedicadas a la enseñanza de la música -unas creadas por la iniciativa privada y otras de origen estatal- en el estado de Chiapas; veremos cómo algunos de sus jóvenes estudiantes, utilizando sus habilidades organizacionales o talentos innatos, trascienden y superan las expectativas de las orquestas y bandas musicales de las que forman parte. Otros, por su parte -la gran mayoría-, no podrán superar las condiciones de precariedad social y aprenderán música aun en contra del medio que los circunda. En los casos extraordinarios, su desempeño se vuelve más notable al desarrollarse en condiciones de precariedad económica y cultural, al trascender las limitaciones económicas en las que han nacido para adentrarse en el mundo de la música, ya sea como un oficio o como el desarrollo de un talento individual, pero siempre en el entramado de las instituciones y la sociedad que los envuelve.

\section{Institutions, music, youth people and children in orchestas and muscial bands}

\begin{abstract}
Exploring two different institutions dedicated to the teach music, one created by private initiative and the other by the state, in the State of Chiapas we will see how some of their young students, using their organizational skills or innate talents, transcend and exceed the expectations of the orchestras and bands they are part of. On the other hand, other, the great majority, will not be able to overcome the conditions of social precariousness and will learn music even against the environment that surrounds them. In extraordinary cases,
\end{abstract}

\section{Palavras-chave}

Niñez; Jóvenes; Música; Crianza; Chiapas

\section{Palabras clave}

Childhood; Youth; Music; Nurturing; Chiapas 
their performance becomes more remarkable when they develop their talents in very difficult conditions of economic and cultural precariousness. Some of the transcend their environment to explore music as a way of develop an individual talent, but always in the framework of the institutions and society that surrounds them.

\section{Instituições, música, crianças e jovens em orquestras sinfôni- cas e bandas musicais}

\section{Resumo}

Palavras-chave

Infância; Juventude; Música; Criação; Chiapasa
Explorar duas instituições dedicadas ao ensino da música, uma criada por iniciativa privada e outra pelo estado, no estado de Chiapas; Veremos como alguns de seus jovens estudantes, usando suas habilidades organizacionais ou talentos inatos, transcendem e superam as expectativas das orquestras e bandas das quais fazem parte. Outros, por outro lado, a grande maioria, não serão capazes de superar as condições de precariedade social e aprenderão música mesmo contra o ambiente que os cerca. Em casos extraordinários, seu desempenho se torna mais notável quando se desenvolvem em condições de precariedade econômica e cultural, transcendendo as limitações de recursos que os cercam para explorar a música como um comércio ou o desenvolvimento de um talento individual, mas sempre no estrutura das instituições e da sociedade que as cerca.

\section{Introducción}

De acuerdo con McDowall (2010) las tradiciones sociológicas y antropológicas -así como las perspectivas históricas (Ariés, 1960)- inauguraron el campo de estudio de la infancia como un estadio subalterno al mundo adulto. Estadio o etapa transitoria que preparaba al niño para su inminente llegada al mundo adulto, momento en el cual entonces sí su desarrollo sería pleno. Hasta entonces, el niño sería objeto de las instituciones y normas. En esta lógica adultocéntrica es que se vuelven notables las obras literarias o películas en que los niños son protagonistas que encarnan pasiones humanas, reflexiones políticas o capacidades solo atribuidas a los adultos. Un ejemplo de esto son Las aventuras de Tom Sawyer (1997) publicadas originalmente entre 1876- 1978 por Mark Twain. O la película francesa Zéro de conduite del directo Jean Vigo estrenada en 1933. En el extremo opuesto encontramos El señor de las moscas (1954) de William Golding, película en que se representa el grado de barbarie al que pueden retrotraerse los niños sin la observación de los adultos, sin una escuela, sin un Estado. Aunque no son pocas las obras de ese tipo, son mucho más abundantes los títulos y películas en que se representa al infante sobrecargado de rasgos de inocencia, dulzura; atribuciones que se consideran parte inherente a su estadio infantil. Al respecto, es necesario señalar que los niños y jóvenes que participan en las bandas y orquestas musicales del México rural observadas para este estudio, merecen una mención especial solo por el hecho de embarcarse en una travesía casi imposible, cuando su ambiente inmediato les demanda necesidades mucho más básicas como comer, estudiar o simplemente sobrevivir. 
En el mundo de lo social no contamos con un momento consensado universalmente que marque la transición de la infancia hacia la adultez. Entonces, colectivamente les hemos conferido a las instituciones determinar cuándo es este el momento y los procesos que procuran su maduración; es decir, los que permiten llegar a la adultez. Nos referimos al tránsito de la persona por la escuela primaria, la secundaria, la universidad etc.; es decir, su paso por las instituciones. En este sentido, la imagen de las niñas, niños y jóvenes, tal como se les concibe hoy en día, son producto también de la llamada modernidad.

Es a finales del siglo pasado y comienzos del presente, que estudios como los de Liebel (2003) incluyen en su análisis el carácter contextual de la diversidad cultural. A partir de entonces, en otros trabajos de perspectiva antropológica comenzamos a identificar, registrar y teorizar en torno a la particularidad cultural en que niños y jóvenes se desenvuelven (García, 2016; Ramírez, 2015; Magazine y Ramírez 2007). La inclusión del enfoque antropológico permite voltear la mirada a las diversas formas en que niñas y niños contribuyen y ayudan a los grupos domésticos a los que pertenecen, a cómo se reproducen en sus contextos culturales, lo que a su vez permite identificar los múltiples significados de lo que un niño puede ser alrededor del mundo.

Curiosamente, para su "estudio", en primer término pasamos años aislando de sus contextos a los niños y jóvenes, para en forma posterior, en otro ejercicio académico, vincularlos nuevamente con estructuras como la familia, instituciones académicas, la economía, etc. Con estas consideraciones en mente, en el presente trabajo nos asomamos a la dimensión cultural y musical en que se reproduce la vida de algunos jóvenes mestizos e indígenas chiapanecos. Con este fin exploraremos dos estudios de caso, por un lado la Orquesta Sinfónica Esperanza Azteca de Tuxtla Gutiérrez, Chiapas, México, de aquí en adelante nos referiremos a ésta como OSEA y por otro lado abordaremos las casas de cultura de la región de los Altos de Chiapas. Veremos cómo niñas, niños y jóvenes con sus esfuerzos individuales o colectivos recrean y se desplazan en los entramados institucionales y la música; todo esto en condiciones de precariedad e incertidumbre. Exploramos entonces cómo, en ambas instituciones, individuos jóvenes con cualidades innatas sobresalientes para la música o habilidades organizacionales son capaces de desempeñar diversos roles y en ocasiones revirtiendo las reglas para intervenir directamente en la organización de las instituciones y en la reproducción de la música.

\section{Metodología}

El trabajo de campo se desenvolvió en dos etapas, primeramente entre 2014 y 2015 se trabajó con las OSEA se realizó en Tuxtla Gutiérrez, capital del estado de Chiapas. Posteriormente, entre los años 2016, 2017 y 2018, con las casas de cultura de los municipios de San Juan Cancuc, San Juan Chamula, Zinacantan, Tenejapa y Chalchihuitan. En estos años pudimos observar cómo ciertos niños, que destacan por alguna cualidad, carácter, talento o habilidad, suelen y pueden cumplir roles de suma importancia en el desarrollo de las actividades totales, recreativas, organizativas y de aprendizaje en ambas instituciones.

Exploramos las estructuras que las componen, las dinámicas y roles que permiten su funcionamiento, así como el uso y los diversos desempeños que realizan las niñas y niños dentro de ellas. De acuerdo con Barfield (2000), Gaitán (2006), Rodríguez (2007) y Weisner (1996), el trabajo etnográfico nos puede ayudar a 
registrar e identificar los momentos de participación de los sujetos en diversos contextos; estando ahí presentes en algunas clases de música y hablando con los maestros pudimos saber más acerca de las trayectorias de algunos de ellos. Como complemento, se realizaron talleres de mapas de vida, un instrumento de investigación que consiste en proporcionar al niño o joven una cartulina y plumones de colores, así como algunas indicaciones básicas que sirven como guía para dar inicio a un dibujo libre con el tema Mapa de mi vida. Este taller nos permite conocer sus experiencias, sentimientos y creencias. Es un excelente medio para identificar su vínculo con una organización, al tiempo que se convierte en una herramienta muy útil que respalda el trabajo con niñas y niños.

Recorrimos los alrededores de las comunidades para conocer los sitios más significativos donde se sitúan las OSEA y las casas de Cultura; registramos también las actividades de los niños y jóvenes, sus espacios de interacción, salones de clase, el patio y los conciertos. Por último, identificamos sus dinámicas dentro y fuera del proyecto, como charlas formales e informales, juegos, y los ensayos.

\section{La trayectoria, los jóvenes y la música}

El estudio de las instituciones educativas tiene una metodología muy particular, que permite, entre otras cosas, registrar los sistemas de control y evaluación de la actividad institucional así como los elementos que la componen y las practicas que desarrollan (Piña Osorio, 2013).

Así pues, el estudio de la institución, del proceso educativo y de la infancia/ adolescencia nos permitirá entender de forma integral cómo se van "creando" los adultos en el entramado institucional, lo que para Anzaldúa (2012) permite la creación de nuevas subjetividades -por ejemplo, debido al acceso a las nuevas tecnologías y la circulación e intercambio de información, entre otras cosas-. En algunos municipios rurales del país, los miembros jóvenes de las bandas de música no solo se acercan a las nuevas tecnologías, sino que se caracterizan por mantener un nexo muy profundo con lo definido como tradicional (De Agüero, 2005).

La utilización de las trayectorias como técnica de investigación permite, en temas como el que aquí nos ocupa, conocer la ruta educativa o laboral de jóvenes y niños en su tránsito a la adultez. Diversos autores sugieren también que esta metodología posibilita identificar la forma en que los individuos toman decisiones dentro de los entramados institucionales o educativos. Algunos de los partidarios de esta perspectiva consideran incluso podría contribuir al correcto desarrollo y aplicación de políticas públicas (Sepúlveda, 2010). Litichever $(2006,2014)$ ha realizado un interesante retrato de las relaciones que se producen entre las instituciones, la calle y las trayectorias individuales de jóvenes urbanos. Pero en el caso de los trabajos con jóvenes indígenas mexicanos estos tipos de estudios son escasos, lo que limita nuestro conocimiento sobre sus trayectorias y los factores que influyen en su toma de decisiones. La investigación sociológica y antropológica contemporánea concluye que la marginación de este sector de la población no es solo institucional, sino también académica, debido, entre muchas otras cosas, a la manera en que los pueblos originarios fueron integrados periféricamente al imaginario de la nación mexicana. 
Cuestión innegable es que en el campo o en la ciudad, en el sur o el norte del continente, los niños y los jóvenes han sido y son objeto de disputa de las políticas desarrollistas y conservacionistas (Rodríguez, 2018). La juventud se concibe como un objetivo claro de las políticas públicas, debido a que están más cerca de ejercer sus derechos ciudadanos. En el caso de los municipios indígenas mexicanos, dicho ejercicio se posponen y se ejercen de manera excepcional en época de elecciones federales, estatales y municipales. No es de extrañar que en el diseño de las políticas culturales en zonas rurales en México se determine "a priori" cuáles son los renglones de la cultura que recibirán financiamiento en cada periodo de gobierno. Por ejemplo, en estados como Oaxaca, Chiapas o Guerrero -algunos de los más pobres-, se decide apoyar aspectos de la cultura, tales como talleres de oficios o habilidades que se consideren más "propias" de la cultura local. En contraste, en los municipios más urbanizados o en las grandes ciudades se apoyan los talleres de ballet, teatro $u$ otras artes escénicas. Incluso la música que aprenden y reproducen es diferenciada: en las orquestas musicales se toca música de origen europeo, fusiones o la llamada música mexicana, que es más bien mestiza; mientas que las bandas musicales tocan, en los casos que vemos aquí, piezas que buscan recuperar o preservar lo que se considera tradicional. Su estilo está más bien determinado por el grado de mestizaje que ostenta cada grupo. Es en este tipo de tramas institucionales que quedan atrapados los jóvenes que participan en las orquestas musicales. Aunque los jóvenes alumnos buscan darle vuelta a las reglas y normas a su favor. Ya que desde hace unos 15 años aproximadamente hay una ola importante de bandas de rock, rock pop, metal, black metal en las comunidades, principalmente originarias de Zinacantan, San Juan Chamula, Cancuc, que componen e interpretan música original en tsotsil y tseltal. Por ejemplo, Vayijel, Sak Tzevul, entre muchas otras, que en ese caso se encuentran en una negociación constante con las autoridades tradicionales de sus comunidades sobre qué es posible cantar o que no. El caso de las agrupaciones indígenas de música no tradicional merece un estudio aparte y no ahondaremos en ellas en este momento. Aun así, la música siempre promete ser una aventura para todo aquel que desee tomar esos riesgos. Por ejemplo, algunos jóvenes buscan participar en ellas, ya que les permite estar en un ámbito socialmente aceptado y a la vez alejarse de la supervisión familiar.

Esto es posible gracias a los continuos viajes que debe realizar la banda $\mathrm{u}$ orquesta, lo que les permite liberarse de la rigurosa observación de los padres. Para apreciar estas relaciones de manera más cercana, el enfoque biográfico es de gran utilidad, pues permite analizar lo colectivo y lo individual (Roberti, 2012). También el estudio de las bandas musicales es un espacio privilegiado, pues en estas se observan contradicciones a nivel institucional, comunitario; así como tensiones entre lo individual y lo colectivo, las aspiraciones personales y las posibilidades de que se cumplan (Martínez, 2009).

En el caso de los aprendices o jóvenes músicos, se les exige en muchos casos su compromiso y su participación total para que la banda u orquesta musical funcionen, aunque esta no cuente con recursos ni instrumentos apropiados. Tal es el caso de las bandas musicales de la mayoría de los internados interculturales del estado de Oaxaca (Ramírez, 2016b). La diversidad cultural y política del país muestra también que no todas las bandas funcionan igual; que existen las que tienen ingresos regulares, ocasionales; las que dependen de diferentes organizaciones y las que dependen totalmente de las aportaciones que hacen los migrantes. Como se observa en el caso de la banda de música 
de San Pedro Tlalcuapan, Tlaxcala (Ramírez, 2016a). En Tlalcuapa, la asamblea de migrantes que reside en Oxnar y Costa Mesa, California, Estados Unidos, reúne y envía anualmente dinero para los instrumentos y uniformes de los jóvenes, para que tengan, en sus palabras, unas de las mejores bandas. Las bandas de música como estas son las que preferentemente ejecutan valses y otras piezas de música mestiza y no música tradicional mexicana.

En contraste, en el caso de la Casa de Cultura de Chiapas, el Profesor Enrique, pionero de la promoción y protección del patrimonio cultural, ahora exdirector del Centro de Artes Lengua y Literatura Indígena (CELALI), enfatizó en una entrevista la necesidad de tener casas de cultura "del pueblo", en las cuales se priorice la lengua y la música de los pueblos originarios. En estas casas, la música que se busca preservar y ejecutar es aquella de origen mayense en sus diversas variantes: tsotsil, tsetal, tojolabal, entre muchas otras.

Otros esfuerzos mucho más modestos son los de las bandas familiares como los grupos musicales de Tlaxcala y otros estados, en los que el padre educa a los hijos en la tradición musical para formar un grupo de mariachi o una banda de vientos. Es común en casi todos los estados del país, ver a hombres adultos acompañados de niños pequeños que están aprendiendo a tocar un instrumento, ejecutando algunas piezas consideradas tradicionales.

\section{La música}

Trabajos como los de Agudelo (2006) resaltan que las diversas influencias que alimentan la llamada música mexicana, tanto en su melodía contemporánea, así como la forma de organizar las bandas de aliento metal y las orquestas sinfónicas son producto de un ensamblaje cultural, lingüístico étnico fraguado desde la colonia hasta el surgimiento del México posrevolucionario. ${ }^{1}$ Tenemos entonces que la llamada "identidad sociomusical", categoría propuesta por Ramírez Paredes (2006), que no es estática, sino que se transforma con el tiempo. Sin embargo, al tratarse de un fenómeno generado por una colectividad que comparte un gusto musical, crea una identidad. Esta identidad, aunque dinámica, se establece entre los miembros de una banda u orquesta musical, y en todo caso será lo que permita a los jóvenes en espacios rurales, urbanos o intermedios a permanecer en estos a pesar de las dificultades, de la falta de estructura o de recursos. Si bien la creación y apoyo a las orquestas y bandas musicales ha sido continua desde los gobiernos posrevolucionarios, particularmente a finales de la década de los años treinta (Ejea, 2006), en el caso de la música ejecutada por jóvenes en el estado de Chiapas varía de acuerdo con su grado de contacto con otras influencias, su grado de mestizaje, politización, o incluso con el nivel de reflexión sobre la importancia de recuperar la lengua y la música tradicional.

\section{Las casas de cultura y los niños músicos}

En el periodo comprendido entre 1994 y 1997 se realizaron las gestiones políticas y administrativas necesarias para la creación del (CELALI). Las pláticas y negociaciones que llevaron a su fundación por decreto se dieron en las mesas de discusión de los llamados Acuerdos de San Andrés en el contexto del levantamiento Zapatista de 1994. Posteriormente a su fundación, al CELALI se le confirió la creación y administración de 17 casas de Cultura, a las que, con el paso de los años, se sumaron, aunque no de manera oficial, otras ocho. 
Todas ellas varían de acuerdo con los recursos disponibles, su accesibilidad, e incluso las construcciones que las albergan son de lo más disimiles; las hay con bellas casas, como la de San Juan Chamula, que cuenta con espacios bien construidos, luz, agua y baños. Y otras mucho menos afortunadas, como la del municipio de Chalchihuitan, que no cuenta con instalaciones apropiadas, no hay agua corriente ni baños, y en ocasiones ni siquiera cuenta con el servicio de luz. Cada casa atiende a diferente número de niños, que van desde los 35 hasta los 95 alumnos inscritos a diferentes talleres; los cuales también varían dependiendo de cada casa, por ejemplo, algunas tienen talleres de pintura, dibujo, poesía, huertos, danza, teatro y música.

En este espacio nos referiremos exclusivamente al taller de música, los cuales funcionan también de acuerdo con sus posibilidades. Por ejemplo, el taller de música de San Juan Cancuc cuenta con instalaciones adecuadas, espaciosas, limpias, instrumentos hermosos, los cuales son ejecutados con maestría por los instructores de música. Ellos se dan a la tarea de rescatar melodías tradicionales, rituales y de fiesta. Al taller de música asisten más o menos 16 niños, que se turnan para usar los instrumentos y aprender las melodías. El actual maestro es un hombre muy joven, Pablo, quien, ataviado con su ropa tradicional, ejecuta una especie de arpa, para después contarnos que él había sido alumno de ese mismo taller y cómo, por haber sido un alumno destacado, llegó a ser maestro. Actualmente ya tiene una plaza de empleado en la Casa de Cultura y recibe un salario por su trabajo. El caso opuesto es el de la Casa de Cultura de Chalchihuitan: ahí el maestro de música es el señor Roberto, quien además de ser promotor cultural, autoridad tradicional, se desempeña también como maestro de música. Él toca la marimba y tiene alrededor de seis alumnos, todos originarios de la cabecera municipal, pues los poblados que pertenecen al municipio están muy alejados del centro. Algunos de sus alumnos son sus parientes y tocan también en las fiestas del pueblo. Las clases son irregulares, la falta de fondos, materiales e instrumentos no detienen el trabajo y el aprendizaje los alumnos. Sin embargo, es frecuente que los encargados de los diversos talleres de la Casa de la Cultura hagan convocatorias y llamados continuos para comenzar a impartir sus clases. Particularmente en esta casa de cultura los encargados son gente muy joven, quienes movilizan todos sus recursos sociales, culturales y organizacionales para sacar adelante, no solo el taller de música, sino todas las actividades, desde la limpieza, hasta convencer a los padres de que dejen asistir a sus hijos a los talleres. Como un alumno que realizó una de las visitas de campo conmigo comentaba "en este ambiente, dedicarse a la música es una extravagancia". Sin embargo, los niños saben que, si le dedican tiempo a esta actividad, quizá, logren enseñar a otros cuando crezcan.

En un proyecto musical oficial -que tiene como propósito una labor educativa-, idealmente se deberían ofrecer los medios básicos para que los alumnos aprendan, ensayen y preparen sus presentaciones. Además, de que cuenten con maestros calificados e instrumentos suficientes, pero al menos en el caso de las casas de Cultura observadas, esto no siempre es posible. Con variantes importantes, observamos que las dinámicas que se suceden entre una y otra son muy desiguales. Citamos unos ejemplos, en la casa de cultura situada en un municipio con larga tradición comercial y turística, es común que los alumnos cuenten con sus instrumentos propios y que asistan regularmente a sus clases. Sí enfrentan otro tipo de dificultades, pero su contacto con otras influencias culturales, incluso su cercanía con la capital cultural del estado, la ciudad de San Cristóbal de las Casas, facilita su acceso a otras influencias. Debido a que la música que aprenden a tocar es muy tradicional, ritual, propia 
de la familia maya tsotsil, la valorización social que reciben los que se dedican a este oficio es muy positiva. En el polo opuesto se encuentra la Casa de Chalchihuitan, alejada de San Cristóbal, situada muy alto en la montaña y que, como comentamos anteriormente es la que cuenta con menos recursos sociales y culturales. Es en esta casa donde cada quien resuelve los problemas de la mejor manera que puede.

En este caso, quien transmite el oficio es un músico nato, Don Roberto. Él también enseña música tradicional tsotsil, pero en esta variante hay más marimba. Aprendió a tocarla de niño; asimismo, él enseñó a sus hijos y a otros niños y jóvenes que asisten a su taller. Don Roberto también toca la marimba en las fiestas y eventos del pueblo. Además, habla castellano de manera más fluida que otros miembros de la comunidad, por eso estaba encargado de realizar todos los trámites de la Casa de Cultura ante el CELALI en San Cristóbal. Es común que esta situación se repita en otras casas, es decir, que el profesor haya aprendido música de manera informal y en la actualidad enseñe a los más jóvenes. También lo es que un mismo maestro esté a cargo de otros talleres o que el profesor que imparte la materia de música sea el alumno más avanzado o un exalumno de la casa de Cultura, tal como sucede en la de San Juan Cancún.

\section{Organización y estructura de las OSEA}

En este apartado profundizaremos en las Orquestas Sinfónicas y Coros Esperanza Azteca (OSEA). Las OSEA son un proyecto social y artístico dirigido a niños y jóvenes de 7 a 18 años, principalmente de escasos recursos, son operadas por Fundación Azteca. Como parte del discurso oficial, el proyecto propone restaurar el tejido social y formar mejores seres humanos a través de la música. Este proyecto está compuesto por 88 orquestas sinfónicas: 85 en el interior de la república mexicana, dos en El Salvador y una en Estados Unidos (Los Ángeles, California). Actualmente, está conformado por 18 mil niñas, niños y jóvenes, y 1300 maestros. Cabe destacar que los estudios realizados en este proyecto no tienen validez oficial ante la Secretaría de Educación Pública (SEP).

Las orquestas ensayan y practican de lunes a viernes, con una intensidad de 20 horas semanales (cuatro horas al día) de práctica grupal supervisada. Esto significa que los maestros deben atender a los alumnos de manera individual sin descuidar al grupo entero, lo cual suele complicarse, sobre todo cuando manejan grupos muy numerosos, como en el coro. Observamos que José Carlos atendía a sus compañeros de forma individual, mientras que el profesor de cello lo hacía con el grupo entero, de manera que se convertía en un trabajo colaborativo entre profesor y alumno.

Los horarios de las OSEA se organizan de cuatro de la tarde a ocho de la noche. En la primera parte de las clases de música se imparte solfeo, instrumento, ensayos. De seis a seis y media es el receso, momento en que los alumnos consumen sus alimentos, practican algún deporte o realizan una actividad física con sus compañeros. Hay quienes prefieren aprovechar este momento de descanso para tocar o ensayar obras del repertorio, ya sea dentro de los salones o en el patio. A las seis y media se reanudan las clases de música. A las ocho de la noche terminan las actividades y todos regresan a sus casas.

Se ha establecido una cuota de $\$ 100$ mensuales, pero hay alumnos que no tienen la posibilidad de cubrir ese pago porque provienen de familias de escasos recursos. Para evitar que estos abandonen su formación musical, el proyecto 
los ayuda para que continúen. José Carlos recibía un pequeño monto de dinero al mes por ayudar como maestro en la orquesta. Una OSEA cuenta con alrededor de 200 alumnos, pero este número puede variar dependiendo de las condiciones del lugar, del tamaño de la sede, del tiempo que lleve activa o del éxito de la difusión, entre otros factores. En el caso de José Carlos, pertenecía a la orquesta local y a la nacional, lo que le permitía participar en giras a la vez que adquirir mayor experiencia musical.

Dependiendo de la actividad, se realizan diferentes tipos de conciertos: conciertos de fogueo, conciertos programados, conciertos de gala y conciertos debut; este último el más importante, ya que es el de inauguración de una orquesta. A nivel simbólico, el concierto debut es un avance, porque así se obtiene el derecho a tocar en otros lugares y salir de gira. También representa la culminación del trabajo en equipo entre directivos, maestros, alumnos y familiares. Detrás del concierto debut existe una compleja organización que nos demuestra el entusiasmo y las habilidades de niños y jóvenes para la música.

De acuerdo con el tiempo y experiencia musical de los alumnos, hay tres tipos de orquestas. La orquesta tipo A es la orquesta inicial: en ella tocan los alumnos que apenas ingresaron y que no tienen experiencia musical. La orquesta tipo B es la intermedia: en ella tocan los alumnos que llevan más tiempo y que poseen mejor entendimiento musical. Por último, se encuentra la orquesta tipo C, que es la más avanzada: está integrada por alumnos que ya debutaron y que, por tanto, poseen más experiencia y conocimientos musicales. Este tipo de orquesta interpreta obras de mayor complejidad que las demás.

Cada OSEA tiene una plantilla mínima de 15 maestros de música (uno de ellos el director artístico, encargado de dirigir la orquesta y el coro). Además, tienen un coordinador local, encargado de los recursos humanos, físicos, financieros y administrativos. Algunas OSEA, como en el caso de Tuxtla Gutiérrez, cuentan con un psicólogo. Aunque los psicólogos no están en la plantilla oficial de maestros, su trabajo es de suma importancia, porque ayudan a los alumnos cuando tienen problemas personales, familiares o emocionales. Los maestros de Música no están capacitados para tratar con problemáticas de este tipo, y los psicólogos, como especialistas, ayudan a los alumnos a resolver estas situaciones.

En el proyecto se realizan cinco actividades principales. En primer término figuran las clases de iniciación musical. A través de juegos y dinámicas grupales, los niños que apenas ingresaron comienzan a familiarizarse con la música y con el proyecto. Son clases muy sencillas, en las que los maestros ponen a prueba las capacidades de los niños. La edad de estos varía dependiendo del lugar y las necesidades de la OSEA. La mayoría son menores de seis años, aunque tuvimos oportunidad de observar mayores (de 14 o 15 años). La segunda actividad son las clases de música, que pueden ser individuales o grupales. Se clasifican en clases de solfeo y de instrumento; para las cuerdas, en técnica de arco; para coro, en solfeo y canto. La tercera actividad es el seccional. Este consiste en agrupar a los instrumentos de una sección en el patio para que toquen juntos. El seccional lo dirige el coordinador de sección. La cuarta actividad es el Tutti. En ella, todos los alumnos de la orquesta sinfónica y del coro tocan y cantan todas las obras del repertorio. En el Tutti también están presentes los coordinadores de cada sección. Los maestros que no son coordinadores de sección se quedan en sus salones impartiendo clases o repasando algunas obras del repertorio. 


\section{Etapas de una OSEA}

La primera etapa consiste en dar a conocer las convocatorias a través de diversos medios de comunicación (radio, televisión e Internet), otras formas de propaganda (como panfletos, videos promocionales en los que participan los alumnos), o por medio de familiares y amigos. La segunda etapa consiste en el examen de admisión, basado en una serie de pruebas de diferente tipo. Los profesores les preguntan sobre el instrumento al que desean entrar, si lo saben tocar y si tienen conocimiento de otros. Posteriormente, con el fin de evaluar su desempeño, se le pide al niño que realice algunos ejercicios de coordinación y de memoria auditiva.

El examen de admisión es sencillo y de corta duración, pero los profesores, por medio de este tipo de pruebas, se percatan de las facultades y habilidades de los aspirantes. Hay niños que tienen gran talento para la música, con ganas de aprender y muy enérgicos, hay quienes incluso llevan su propio instrumento y lo tocan delante de los profesores para demostrarles sus cualidades para la música.

Los aspirantes que no aprueban el examen de admisión pueden volver a intentarlo hasta la próxima convocatoria. Solicitan ingreso todo tipo de niños, de diversos estratos sociales y con distintas capacidades (incluso niños con alguna discapacidad física). En la última parte del proceso se ofrece una demostración de los maestros tocando su instrumento, de manera que los niños conozcan las opciones existentes y puedan elegir mejor.

Una vez hecha la elección, los niños tienen que construir sus instrumentos de cartón y otros materiales muy económicos, hasta que les entreguen los de verdad, aproximadamente un mes después de comenzar con sus clases. Cada alumno contará con el suyo propio (el único que el proyecto les presta) y será responsable de su cuidado y mantenimiento, lo que implica incluso cubrir los daños que pudieran ocurrirle.Cuando los instrumentos necesitan mantenimiento contratan a un profesional o bien son los mismos alumnos quienes los arreglan.

Algunos alumnos prefieren comprar sus propios instrumentos debido a que los que les presta la orquesta son austeros, en toco caso ellos tienen que conseguirlo uno nuevo por sus propios medios. Esto implica que la familia tenga que gastar hasta 15 mil pesos mexicanos, cuando el salario mínimo es de 75 pesos diarios. En ocasiones, no es posible proporcionarles el instrumento que eligieron. Esto se convierte en un inconveniente porque, por ejemplo, si un niño quiere ingresar a clases de violín y ya no hay cupo, entonces lo colocan en el grupo de coro o en alguna otra sección de la orquesta, con lo cual se presentan casos en los que se pierde el interés por continuar. Aunque también puede pasar lo contrario y terminan mostrando más interés por el nuevo instrumento que se les asignó. Esto depende de cada niño.

La siguiente etapa es el concierto debut. Los alumnos tienen que prepararse durante un año para debutar en algún teatro o sala. En su etapa de conformación, las OSEA no pueden ofrecer conciertos, es así que la primera aspiración es llegar al concierto debut. A este concierto asisten gobernadores, directivos de Fundación Azteca, familiares y amigos de los alumnos. Se trata de un evento altamente ritualizado, que representa una experiencia significativa de cambio en la vida estos niños y jóvenes. Para distinguir el "rango" o posición que ocupan dentro de la orquesta, se optó por asignarles uniformes con diferentes 
colores: las camisetas blancas las utilizan los recién egresados que todavía no debutan; las de color verde son para los integrantes del coro; las rojas son para quienes pertenecen a la sección de cuerdas; las amarillas para la sección de aliento-metal; y las azules son para las percusiones.

\section{OSEA Tuxtla Gutiérrez}

La OSEA Tuxtla Gutiérrez (en adelante, OSEA TG) está ubicada la capital del Estado de CHiapas. Esta tiene su propia sede, un edificio de tres pisos situado en 3 Oriente Norte, \#142, col. Centro Tuxtla Gutiérrez. El director artístico es Rodrigo Díaz Bueno, tiene 42 años, de origen español, quien también es maestro de cello. La coordinadora local es Ada Sánchez Rojas, de origen mexicano.

Esta OSEA imparte clases en la mañana (de 8:00 a.m. a 12:00 p.m.) y en la tarde (de 4:00 p.m. a 8:00 p.m.). En el turno de la mañana (también llamado Curso Propedéutico) hay aproximadamente 70 alumnos, y en el de la tarde, 360. El Curso Propedéutico se diseñó exclusivamente para jóvenes con experiencia musical y que desean estudiar música de manera profesional. El turno de la tarde se pensó para totalmente principiantes. Estos niños y jóvenes, al debutar tienen derecho a ingresar al Curso Propedéutico de la mañana. Una característica muy importante de esta OSEA es que, por un lado, se combina concretamente el aspecto social con el musical, ya que se utiliza la música como elemento de integración grupal y de desarrollo de habilidades y facultades; y por el otro, permite a los alumnos más avanzados ayudar a sus compañeros menos experimentados en las clases.

\section{Músicos extraordinarios en condiciones de precariedad insti- tucional}

Al respecto es muy significativo el caso de José Carlos Ruíz, de 17 años, alumno de cello en el Curso Propedéutico de la OSEA, porque tiene una habilidad inusual para la música que lo hace sobresalir notablemente respecto de sus otros compañeros, y que le permite desempeñar un papel esencial en el desarrollo y crecimiento de la orquesta: el oído absoluto. Durante el trabajo de campo, se observó que José Carlos apoyaba a sus compañeros en lo referente a teoría y práctica musical. Por petición de su profesor de cello, Rodrigo Díaz, se le daba oportunidad de dirigir la orquesta tipo A (orquesta inicial) en el turno de las tardes. Constantemente, Rodrigo Díaz platicaba con él y le daba consejos, incluso le pedía que por ningún motivo abandonara el proyecto, ya que sus habilidades para la música eran una pieza clave para el desarrollo y prestigio de la orquesta.

En una ocasión observamos a José Carlos interpretar la Suite no. 1 en G mayor, de Bach, sin apoyo de ninguna partitura. Esta obra es muy conocida entre los cellistas y difícil de tocar. Muchos de sus compañeros sentían una admiración profunda por él, ya que, entre otras cosas, memorizaba increíblemente rápido cualquier obra del repertorio; sin embargo, como suele ocurrir en el ambiente de la música, no faltaba quien sintiera envidia por sus talentos, lo que generaba conflictos dentro del proyecto.

José Carlos posee facultades y habilidades que le permiten ser como una "bisagra" en el proyecto; es decir, por un lado, desempeña el papel de alumno de cello, que toma clases de manera normal; y por el otro, juega el papel de 
maestro y director de la orquesta inicial, en la que ayuda a sus compañeros, lo que a su vez le permite moverse en la estructura del proyecto.

El caso de José Carlos evidencia también las fallas estructurales del proyecto, ya que en ocasiones este alumno tenía que hacerse cargo de grupos que no eran de su obligación. Había momentos en que los maestros de Música no asistían a sus clases, o simplemente no había un maestro que diera la clase, y José Carlos se tenía que hacer cargo del grupo, lo cual nos parece hasta cierto punto injusto porque no le pagaban por hacerlo, aunque sí es verdad que obtenía beneficios de otro tipo.

Es importante aclarar que actualmente José Carlos ya no forma parte del proyecto, debido a que decidió estudiar música de manera profesional en la Universidad de Ciencias y Artes de Chiapas (UNICACH).

Otro caso que llama la atención por su carrera extraordinaria como músico es el de Xun L., él es un músico y pintor tsotsil que surgió de la Casa de Cultura de San Juan. Tempranamente aprendió a tocar violín y guitarra; en la casa de cultura mejoró su técnica y aprendió pintura. Incluso en el año 2017 montó una exposición de pintura en el museo Nabolom, de San Cristóbal de las Casas. A la edad de 23 años Xun llegó a coordinador de la Casa de Cultura donde había estudiado. Pero en pláticas informales me comentó que en algún momento fue estudiante de la OSEA de Tuxtla Gutiérrez; su talento e iniciativa individual le permitió transitar por esas instituciones de manera exitosa. Incluso en el mismo año invitó a la OSEA a realizar un concierto en la explanada de la Casa de Cultura con motivo de las fiestas patronales de San Juan. Los casos aquí llamados Xun y José Carlos son ejemplos excepcionales en una trama institucional que se pone como objetivo el desarrollo de las habilidades musicales y sociales de las niñas y niños de escasos recursos. Sin embargo, su éxito en mucho tiene que ver con sus capacidades individuales, talentos musicales, el hecho de que hablen el castellano de manera fluida, su acceso a otras fuentes de información. Don Roberto de Chalchihuitan también poseyó esos talentos, pero el que se desarrollara en condiciones de verdadera adversidad económica y social impidió que llegara a formar parte de grandes grupos musicales.

\section{Observaciones finales}

En este texto nombramos "José Carlos" a un ejemplo particular de cómo un joven puede contribuir en el aprendizaje musical de sus compañeros. Otorgamos el nombre de Xun a un joven músico extraordinario que transita de una institución a otra, y que pasa de ser el alumno más adelantado de su clase hasta llegar a ser director de la Casa de Cultura, ninguno de estos casos se repiten con frecuencia en otras bandas u orquestas. Son actores con capacidades propias que trascienden la instrucción de los adultos, con capacidades propias en un espacio que frecuentemente atrapa en sus estructuras institucionales los talentos de los jóvenes y niños.

Los casos de José Carlos y Xun ilustran cómo sujetos jóvenes pueden jugar un papel muy importante en la reproducción y en el funcionamiento de espacios dedicados al arte y la música cuando ponen sus facultades y habilidades al servicio de los demás. José Carlos posee facultades y habilidades que le permiten funcionar como una "bisagra" en el proyecto. Como comentamos anteriormente, su papel es crucial al articular diversas estructuras y niveles dentro de instituciones que laboran en la precariedad, con falta de maestros. 
En otras bandas como en el caso de la banda de música de Zoogocho, los alumnos mayores también se hacían cargo del ensayo y aprendizaje de los más jóvenes.

Y en el caso de Xun, y de algunos maestros de las casas de Cultura, donde la constante es la carencia, su tránsito por las diversas estructuras y puestos de los talleres de música permiten ver que son sujetos extraordinarios, cuando un porcentaje alto de alumnos de estos talleres abandonan las actividades culturales para atender demandas que en ese contexto son mucho más urgentes. Un estudio profundo de los diversos grupos y bandas musicales de este tipo pueden mostrar las habilidades y potencialidades de los niños y jóvenes que poseen un talento artístico impresionante en contextos de carencia y entre quienes sobresalir depende casi únicamente de sus talentos. Desafortunadamente, las políticas en materia cultural privilegian otras áreas o temas. Consideramos que es importante crear un mecanismo práctico que detecte o haga visibles las habilidades y facultades sobresalientes de niños y jóvenes -ya sea en el ambiente de la música como en cualquier otro contexto social- para un mejor desarrollo personal y aprovechamiento grupal.

Estos casos brevemente comentados nos sirven como un ejemplo ilustrativo para detectar (visibilizar) y canalizar las facultades y habilidades sobresalientes de otros niños, y resaltar la importancia de estas en el desarrollo integral de la infancia. Nos percatamos también de que, en el espacio de aprendizaje de las artes, sobre todo en el caso de la música, los roles pueden ser modificados, algo que no necesariamente sucede en otras áreas del conocimiento. En el proyecto de las OSEA, por ejemplo, esto es muy claro, ya que José Carlos ayuda y a veces sustituye a sus profesores de música. En el caso de las bandas de Chiapas y en otros estados del país, los alumnos más grandes y con mayor experiencia musical se hacen cargo de aquellos alumnos que recién hacen su ingreso.

En el caso de las casas de Cultura de Chiapas, el alumno más avanzado incluso puede llegar a ser maestro. En el caso de Tlaxcala, el aprendizaje de la música no es una materia más, sino que representa un oficio de suma importancia para el núcleo familiar y para la comunidad entera. En el caso de José Carlos observamos que, al tener capacidad de agencia, tiene la opción de elegir el rumbo que quiere seguir. A pesar de la opinión de los adultos o de las reglas de la institución, fue capaz de tomar la decisión importante de dejar el proyecto, lo que al mismo tiempo tiene un impacto positivo o negativo en la estructura de la orquesta. 


\section{Q Referencias bibliográficas}

" Agudelo, G. (2006). La música y su historia en México. Estados Unidos: Organización de las Naciones Unidas para la Educación, la Ciencia y la Cultura (UNESCO).

» Ariès, Philippe ([1960] 1987): El niño y la vida familiar en el Antiguo Régimen, Madrid, Taurus.

»Anzaldúa Arce, R. (2012). Infancias y adolescencias en el tramado de los procesos de subjetivación. Tramas, 36, 177-208.

» Barfield, T. (2000). Diccionario de Antropología. Oxford: Siglo XXI.

»De Agüero, M. y Muñoz, M. (2005). Momentos de belleza educativa. La escuela, y la música de San Bartolomé Zoogocho. En M. Zorrilla (Coord.), Hacer buenas prácticas. Mientras el debate pedagógico nos alcanza. México: Investigación Educativa. 41-77.

»Ejea Mendoza, T. (2006). La política cultural de México en los últimos años. Casa Abierta al tiempo. Laberinto, $V(5)$.13-25

"Gaitán, L. (2006). Sociología de la infancia. Madrid: Síntesis.

" García, A. T. Cruz y Mena, R. (Coords.) (2016). Género y juventudes. Chiapas: Colegio de la Frontera Sur San Cristóbal de las Casas.

" Liebel, M. (2003). Infancia y trabajo. Para una mejor comprensión de los niños y niñas trabajadores de diferentes culturas y continentes. Perú: IFEJANT.

» Litichever, C. (2006). El entramado institucional de atención a la infancia: un análisis sobre las trayectorias institucionales de los jóvenes que vivieron en hogares. Buenos Aires: FLACSO.

» Litichever, C. (2014). Entre la calle, la escuela, y las instituciones: trayectorias institucionales de jóvenes. Revista Latinoamericana de Ciencias Sociales, Niñez y Juventud, 14, 177-190.

» Magazine, R. y Ramírez Sánchez, A. (2007). Continuity and change in San Pedro Tlacuapan, México: Childhood, Social Reproduction, and Transnational Migration. En J. Cole y D. Durham (Eds.), Generation and Globalization. Youth, Age, and Family in the New World Economy. Estados Unidos: Indiana University Press. 75- 99.

» Martínez Noriega, D. (2009). Identidad, juventud y música pop. Tramas, 31, 169-184.

» Piña Osorio, J. (2013). Investigación Educativa ¿Para qué? Perfiles Educativos, XXXV(139). 29-43.

»Picún, O. y C. Carredano. (2012). El nacionalismo musical mexicano: una lectura desde los sonidos y los silencios. En F. Ramírez, L. Noelle y H. Aciniega (Coords.), El arte en tiempos de cambio y 1810-1910-2010. Instituto de Investigaciones Estéticas. 19- 27.

»Ramírez Sánchez, M. A. (2016a). Trabajo e infancia en Tlaxcala. El caso de San Pedro Tlalcuapan. Talxcala: SEP.

»Ramírez Sánchez, M. A. (2016b). Aprender a ser. Orígenes y experiencia educativa de los Centros de Integración Social (CIS). En N. Rebolledo (Coord.), Aprender a aprender. Nuevas rutas en Pedagogía. México: CONACULTA, SEP. 74-92.

"Ramírez Sánchez, M. A. (2015). “El papel del trabajo y la ayuda en el proceso de reproducción social de la familia indígena-campesina”. En José Rangel Manuel y Beatriz Adriana Servín. Reconfiguraciones familiares en el México de hoy: Miradas crítica. Edit. Miguel Ángel Porrúa. 
》 Ramírez Paredes, J. (2006). Música y sociedad: la preferencia musical como base de la identidad social. Sociológica, 21(60), 243-270.

» Roberti, E. (2012). El enfoque biográfico en el análisis social: claves para un estudio de los aspectos teórico-metodológicos de las trayectorias labores. Revista Colombiana de Sociología, 35(1). 112-134.

» Rodríguez Pascual, I. (2007). Para una sociología de la infancia: aspectos teóricos y metodológicos. Madrid

»Rodríguez, E. (2018).Emput@dos y disput@dos: miradas neoliberales, neoconservadoras y neodesarrollistas sobre l@s jóvenes en América Latina. Colombia: CLACSO. Colección Grupos de Trabajo.

" Ruíz, R. (2016). Música y banda musical desde la Gran Década Nacional hasta el fin del Porfiriato. Cuicuilco, 23(66). 51-74.

"Sepúlveda, L. (2010). Las trayectorias de vida y el análisis de curso de vida como fuentes de conocimiento y orientación de políticas sociales. Perspectivas, 21, 27-53.

» Twain, M. (1997). Las aventuras de Tom Sawyer. Edición digital basada en la $12^{\underline{a}}$ edición de Madrid, Espasa-Calpe, 1997 (Colección Austral ; 212) . Disponible en http://www.cervantesvirtual.com

»Weisner, T.S. (1996). Why ethnography should be the most important method in the study of human development. In Education and ethnography. Jessor, R., Colby, A., \& Shweder, R., (Eds.).97-114. 